\title{
Sebastián de Benavente y la orden franciscana
}

\author{
Juan María CRUZ YÁBAR \\ Conservador del Museo Arqueológico Nacional \\ juan.cruz@mcu.es
}

Recibido: 10 de marzo de 2011

Aprobado: 22 de septiembre de 2011

\section{RESUMEN}

El arquitecto de retablos Sebastián de Benavente trabajó de manera continuada para los franciscanos al menos entre los años de 1653 a 1667. Realizó obras fundamentales de la orden para conventos de Madrid, Alcalá de Henares (capilla de San Diego), Toledo y Valladolid. Hemos descubierto el retablo de la Puebla de Montalbán, que se tenía por desaparecido, y aportamos el contrato para el retablo de las Clarisas madrileñas, que nos sirve para reconstruir su aspecto original. Analizamos las obras que hizo y le atribuimos algunas de ellas como las de Santa María de la Cruz en Cubas de la Sagra.

Palabras clave: Sebastián de Benavente, Retablos, Franciscanos.

\section{Sebastián de Benavente and the Franciscan Order}

\begin{abstract}
Sebastián de Benavente, altarpieces' architect, worked continually for Franciscans, at least between the years 1653 and 1667. He made fundamental works of the order for convents in Madrid, Alcalá de Henares (San Diego chapel), Toledo and Valladolid. We have discovered the Puebla de Montalbán altarpiece, which it was thought as missing, and we contribute the contract for the altarpiece of Santa Clara in Madrid, which is useful to the reconstruction of the original aspect. Also we examine the works that he made and adscribe some of them as those in Santa María de la Cruz in Cubas de la Sagra.
\end{abstract}

Keywords: Sebastián de Benavente, Altarpieces, Franciscans.

\section{SUMARIO}

Sillería de coro del convento de Santa María de Jesús de Alcalá de Henares. Retablo mayor y custodia del convento de San Francisco en La Puebla de Montalbán. Retablo y custodia, cuatro colaterales, urnas de plata y de mármol y jaspe y otras obras para la capilla de San Diego en el convento de Santa María de Jesús de Alcalá de Henares. Retablo mayor y custodia del convento de Jesús y María de Valladolid.Retablo mayor y custodia, dos colaterales y librería del convento de San Antonio de Escalona. Portada de la iglesia del convento de Santa María de Jesús en Alcalá de Henares. Retablo mayor y custodia del convento de Santa Clara en Madrid. Retablo mayor del convento de Santa María de Jesús en Alcalá de Henares (hipótesis). Retablo mayor y tabernáculo de Santa Juana de la Cruz en el convento de Santa María de la Cruz de Cubas de la Sagra (atribución). Retablo de la capilla de Nuestra Señora de la Esperanza en Santa Clara de Alcalá de Henares. 
Sebastián de Benavente trazó y ejecutó retablos para cenobios franciscanos de las ramas masculina y femenina en los años cincuentas y sesentas del siglo XVII. Las localidades a las que se destinaron fueron muy variadas, como Madrid (Santa Clara), Alcalá de Henares (convento de Santa María de Jesús y su capilla de San Diego, y el convento de las Claras), probablemente Cubas de la Sagra (Santa María de la Cruz, conocido popularmente como de Santa Juana de la Cruz), la actual provincia de Toledo (conventos de San Francisco de La Puebla de Montalbán y San Antonio de Escalona), y la ciudad de Valladolid (Jesús y María). Los encargos llegaron a Benavente a través de la propia orden, o bien por el patrocinio real, de Felipe IV para las labores en la capilla de San Diego, y de Mariana de Austria en la portada de Santa María de Jesús. Tampoco faltaron personajes poderosos de la corte, como don Andrés Pacheco, fallecido en 1626, que fue inquisidor general y patriarca de las Indias y dejó cuantiosas memorias para sufragar los gastos del retablo de La Puebla de Montalbán, o don Ventura de Onís, del consejo real, que costeó el retablo de Valladolid. Benavente realizó prácticamente todos, casi una quincena, además de proyectar obras de diferente carácter, como una sillería de coro, dos urnas de jaspes y mármoles y una de plata, ocho pirámides, seis relicarios, una librería, una caja de órgano, una portada y tal vez una reja. Estas fueron ejecutadas también por otros artífices como marmolistas, plateros, un ebanista y un broncista, maestros de obras y canteros y un rejero. Algunas de estas piezas han pervivido (retablos de Montalbán, Valladolid y San Diego y la urna de plata de este santo) y otras han desaparecido, pero podemos reconstruir su aspecto por medio de la documentación y alguna fotografía antigua.

La relación entre Sebastián de Benavente y los franciscanos comenzó el 26 de febrero de 1653, cuando atestiguó el contrato del maestro de albañilería Juan García para el revoco de las bóvedas de los coros alto y bajo de la iglesia conventual del convento de Santa María de Jesús de Alcalá de Henares y de la capilla de San Diego, además de la decoración de sus capiteles y cornisas ${ }^{1}$. Poco después comenzaría a intervenir él mismo, ya sin interrupción. Expondremos a continuación en qué consistieron esas labores.

\section{Sillería de coro del convento de Santa María de Jesús de Alcalá de Henares}

Los ensambladores Juan de San Payo y Francisco González Bravo contrataron en 3 de agosto de 1653102 sillas del coro de este convento por 38.300 reales. Benavente asistió como testigo de conocimiento de los dos artífices al finiquito de la sillería, otorgado en 21 de mayo de $1658^{2}$. Román Pastor recoge una anotación hallada en el archivo de las Claras de Alcalá sobre un préstamo de las monjas de 11.000 reales para pagar estas sillas y otras obras de la capilla que se dice había hecho Benavente ${ }^{3}$. No ha quedado ningún vestigio de esta obra.

1 AGUlló Y COBO, Mercedes, "El convento de San Diego de Alcalá", Cuadernos de Arte e Iconografia, 23 (2003), p. 45-47.

2 AGULLÓ Y COBO (2003), p. 58. El finiquito cita el contrato de 1653 otorgado en Alcalá.

3 ROMÁN PASTOR, Carmen, Arquitectura conventual en Alcalá de Henares (siglos XVI-XIX), Madrid, 1988, p. 225. Los pagos son de 1657 y 1659. 


\section{Retablo mayor y custodia del convento de San Francisco en La Puebla de Montalbán}

El retablo franciscano más antiguo conocido por el momento de Benavente es el que contrató el 23 de octubre de 1653 con los patrones del convento de San Francisco de La Puebla de Montalbán ${ }^{4}$. Eran compatrones el cabildo y deán de la catedral de Cuenca como administradores de las memorias de don Andrés Pacheco, que había sido patriarca, inquisidor mayor y obispo de Cuenca, y el conde de Montalbán, don Alonso Téllez Girón, mayordomo del rey. Los conquenses actuaban representados por don Pedro Pacheco, pariente del difunto obispo, comisario general de la Cruzada y miembro del Consejo real. En el contrato se especifica que don Andrés Pacheco había concertado en la lejana fecha de 7 de julio de 1615 con el padre guardián y religiosos del convento que pagaría el retablo mayor y dos colaterales para la iglesia del convento. Casi cuarenta años después se procedía a cumplir la promesa, aunque de modo incompleto, pues solo se hizo encargo del retablo principal. La razón del retraso debió ser la falta de caudales, que tampoco estaban disponibles en el momento del contrato con Benavente, pues, aunque se estableció un plazo de tres años para concluir el retablo, tardó mucho en acabarse por la irregularidad de los pagos. El conde de Montalbán era deudor de las memorias del obispo por razón de un censo anual, por el que pagaba 1.100 ducados anuales de réditos, y se debieron de aplicar para cumplir la voluntad del fundador, así como una serie de rentas de casas en Madrid.

El encargo a Benavente incluía un retablo y una custodia para el Santísimo, ambos de madera en blanco, lo que suponía que después serían dorados y pintados. El retablo se haría en madera de Balsaín y la custodia en madera de Cuenca. Nada se dice en el contrato de las pinturas y esculturas que habría de llevar, por lo que es claro que iban aparte y no se incluían en la obligación del ensamblador. Retablo y custodia eran de gran tamaño, a juzgar por su alto precio, 4.000 ducados equivalentes a 44.000 reales.

Benavente debía ser autor de la traza, constando su firma junto a la de su fiador, un mercader de sedas de la Puerta de Guadalajara, Juan Bautista Zabala, la del escribano y la de los dos patrones, don Pedro Pacheco y el conde de Montalbán. Se dice que la traza quedaba en poder de Pacheco, que residía en Madrid, quien la debía tener de manifiesto para que el ensamblador pudiera guiarse por ella. Los comitentes habían introducido una mínima modificación respecto al proyecto de Benavente, pues se indica en las condiciones que el pedestal de la custodia no había de llevar cartelas ni caja, como mostraba el dibujo, sino que se haría con vaciados tallados.

Las condiciones del contrato describen someramente algunas características de la arquitectura. Para comenzar, se había de dar a Benavente 1.200 ducados anticipados, con los que haría la custodia, con su basa y sotabasa formando un zócalo con los recuadros vaciados y adornados de talla; se habla de sus tímpanos tallados, por lo que parece que los lados remataban en frontones; en el centro se elevaría sin duda una cúpula. La custodia y el pedestal del retablo, también de madera, se harían en el primer año con este pago. Tras colocarlos en su lugar, se le entregarían 1.000 ducados

${ }^{4}$ AGULLÓ Y COBO, Mercedes, Documentos sobre escultores, entalladores y ensambladores de los siglos XVI al XVIII, Valladolid, 1978, p. 20-21. 
más, con los que había de acabar el primer cuerpo del retablo en el plazo de otro año. Este cuerpo llevaba columnas estriadas con capiteles corintios, al menos cuatro, pues se especifica que había entrecalles donde se situaban lienzos en cuadros tallados y encima de ellos un adorno también de talla; por encima, una gran cornisa. Una vez entregada esta parte, recibiría nuevamente 1.000 ducados para hacer en el plazo de otro año el último cuerpo del retablo, compuesto de un zócalo, cuadro central tallado con hojas y flanqueado por dos machones labrados, y con un remate semicircular cuyas enjutas llevaban decoración de talla, al igual que los machones. Asentado todo el retablo, se le pagarían los últimos 800 ducados.

Nada se dio a Benavente en el momento de la firma del contrato, aunque pocos días más tarde, el 3 de noviembre, compareció ante el escribano el contador del rey Pedro de Cartagena, que otorgó a favor del ensamblador un poder para cobrar del tesorero de las rentas del papel sellado de Cuenca la cantidad de 279.480 maravedís, que equivalían a 745 ducados, 3 reales y 3 maravedís, que esas rentas adeudaban a las memorias de don Andrés Pacheco, con las que se tenía que pagar parte del primer plazo del retablo ${ }^{5}$. Benavente no debía de tener demasiada prisa por empezar la obra, porque tardó varios meses en dar poder a su vez a otra persona para que realizara el cobro en Cuenca. Sucedió el 15 de febrero de 1654 y el apoderado fue el pintor Andrés de Vargas, que residía en aquella ciudad 6 .

Muy indicativo de la lentitud con que marchaban las obras del retablo, seguramente por faltar los comitentes a los pagos que establecía el contrato, es la noticia del 13 de junio de 1656 de que el dueño de la galera que hacía ordinariamente viajes a La Puebla de Montalbán había cobrado 30 ducados por el trabajo de llevar la custodia del retablo desde Madrid a su destino 7 . Poco antes, el 28 de mayo de ese mismo año, Benavente había dado recibo al conde de Montalbán de 1.000 reales que había cobrado a cuenta de su labor en el retablo ${ }^{8}$. Es claro que con lo que había cobrado en virtud del poder en Cuenca y con esos reales se le había terminado de pagar la custodia, que remitía para allá, puesto que su colocación sería independiente y separada del futuro retablo.

El 1 de julio de 1656, Benavente volvió a otorgar carta de pago a favor del conde, esta vez por 6.000 reales que recibía en un efecto que había de cobrar de una persona residente en Toledo9. Así, las cantidades libradas hasta este momento, si es que tenemos noticia de todos los pagos, serían 8.198 reales en 1654 y 7.000 reales más en 1656, un total de 15.198 reales, muy lejos de los 44.000 a que se habían obligado los comitentes, y que superaban muy ligeramente los 13.200 reales del primer pago que habían de hacer como anticipo antes de que el ensamblador empezara a trabajar.

Un documento de 25 de agosto de 1660 revela que el retablo no estaba terminado, y que existían graves problemas para continuar porque no se estaba pagando al ensamblador. Ese día, un administrador de las memorias de don Andrés Pacheco cedía a

\footnotetext{
5 Archivo Histórico de Protocolos de Madrid, prot. 8480, fol. 482-483.

${ }^{6}$ AGULLÓ Y COBO (1978), p. 21.

7 Archivo Histórico de Protocolos de Madrid, prot. 10.005, fol. 39.

${ }^{8}$ AGULLÓ Y COBO (1978), p. 21.

${ }^{9}$ IBIDEM.
} 
Benavente el derecho a cobrar numerosas rentas de arriendos de casas que las memorias tenían en la plaza Mayor de Madrid, así como los derechos que se cobraran por los tendidos que se ponían en la plaza para las fiestas, en la parte que correspondían a dichas casas ${ }^{10}$. La cesión se hacía por el tiempo necesario para que llegara a cobrar todo lo que se le adeudaba hasta los 4.000 ducados del contrato. Las rentas de esas casas que correspondían a la memoria eran la mitad de los arrendamientos que pagaban los inquilinos de la casa; esta mitad ascendía -sumando todas las rentas- a 3.675 reales anuales, que junto a los ingresos del alquiler de los tendidos podrían equivaler a 4.000 reales anuales aproximadamente, una undécima parte del total del contrato. Si no había habido más pagos que los que tenemos registrados, podemos calcular que pasarían aún unos siete años más para que Benavente pudiera dar finiquito de la obra. Probablemente, el retablo se terminaría antes de este plazo si los pagos fueron regulares, puesto que era condición para cobrar los 8.800 reales del último pago que el retablo estuviera acabado y colocado en su lugar. En todo caso, con el ritmo normal de esos cobros, no es probable que tal hecho tuviera lugar antes de 1665.

Afortunadamente hemos descubierto que el retablo ha pervivido, al contrario de lo que se había dicho hasta ahora. Su imagen corresponde a los datos que se extraen del concierto de 1653, siendo en efecto de grandes dimensiones. Tiene un zócalo pétreo y un banco de madera de mayor tamaño. En éste hay dos cuadros con marcos tallados de hojas como los demás. Encima hay dos tarjetillas con el escudo franciscano y a los lados cuatro pedestales lisos en que apoyan las columnas. Los dos centrales se desdoblan hacia el centro, donde estaba la custodia -actualmente desaparecida y sustituida por un arco de diseño moderno-, y una cornisa quebrada sigue esa prolongación. El cuerpo principal tiene cuatro columnas estriadas, corintias y robadas, esto es, faltas de un cuarto de su diámetro y adosadas. Forman intercolumnios en los que se encuentran superpuestos un lienzo grande y otro pequeño. El marco de este último está quebrado por debajo y tiene encima un festón. Cierra este cuerpo un entablamento canónico con cartelas. En el centro del primer cuerpo entraba desde el basamento la custodia, y sobre el espacio que ocupaba queda una hornacina enmarcada por un cuadro con codillos en lo alto para albergar un tarjetón, que a su vez elimina el arquitrabe y el friso del entablamento para detenerse solamente en la cornisa. Ésta sigue también el perfil cortado como en el espacio del tabernáculo. El remate tiene cerchón semicircular, enjutas con pinturas en vez de la talla del contrato, dos machones con racimos que no llegan hasta el frontón curvo, y marco de orejetas y tarjeta para lienzo.

El hallazgo de este retablo es fundamental para determinar la evolución estilística de Sebastián de Benavente, analizable hasta la fecha únicamente desde 1658 a través del dibujo para el retablo de San Diego y el retablo de Jesús y María de Valladolid. La estructura de este ejemplar muestra algunas características que serán típicas en su obra. Aunque algunos marcos no tienen quiebros, aparecen ya otros con codillos pronunciados y tarjetas que remiten claramente a los de Valladolid. También comparten ambos ejemplares la presencia de pequeñas tarjetas entre el banco y el primer cuerpo, y el diseño de la tarjeta de remate. Sin embargo, los pedestales de las columnas carecen de decoración aún, y no aparece todavía el recurso habitual de elevar los ma-

10 IBIDEM. 
chones hasta el frontispicio. Se observa una tendencia clara a destacar la calle central por medio de la entrada de la custodia en el cuerpo principal, el entablamento roto, las columnas centrales robadas y las cornisas quebradas. Estos aspectos derivan en general de los modelos de Pedro de la Torre y Francisco Bautista, y no vuelven a aparecer en la obra de Benavente salvo en ocasiones aisladas. Los esquemas de aquellos dos maestros están latentes, sobre todo por su retablo de la Fuencisla, que muestra los mismos cuadros con leves recortes y con festones en las entrecalles, y el coetáneo de la parroquial de Orgaz, en cuanto a las cornisas o el marco central que entra en el entablamento. Los cortos machones son iguales a los del diseño de la Real Chancillería de Valladolid que hemos identificado como de Bautista, que sirvió para el retablo de la parroquial de Azcoitia y el de Nuestra Señora de la Antigua en Orduña ${ }^{11}$.

Sin embargo, se reconoce ya una evolución respecto a los dos arquitectos mencionados, principalmente en cuanto a la claridad compositiva y la depuración del ornamento, quedando sólo elementos vegetales de carácter barroco. Benavente irá alcanzando progresivamente una síntesis arquitectónica y decorativa que culminará en los retablos de San Diego, Valladolid, Aldeavieja y Santa Isabel de Madrid. Los cuadros serán ya sólo de orejetas, abundarán las tarjetas y festones, el entablamento se unificará e incluso desaparecerá en gran parte, el cerchón del ático tendrá tarjetillas y los machones alcanzarán el frontis. Pese a extenderse la ejecución en el tiempo, no parece que hubiera cambios para adaptar el estilo, porque no se hubieran pagado las correspondientes demasías.

\section{Retablo y custodia, cuatro colaterales, urnas de plata y de mármol y jaspe y otras obras para la capilla de San Diego en el convento de Santa María de Jesús de Alcalá de Henares}

En 2006 presentamos un artículo sobre el desaparecido retablo mayor de la capilla de San Diego en Alcalá, que fue publicado pasados más de dos años ${ }^{12}$, y un año después mereció unas precisiones del historiador norteamericano J. Brown ${ }^{13}$. Por nuestra parte, consideramos conveniente puntualizarlas, sin entrar en otras aseveraciones suyas acerca del dibujo, que por falta de espacio dejamos para otra ocasión.

Según Brown, el trabajo pretende rectificar la atribución a Cano del dibujo de ese retablo, realizada en 1986 por el profesor Pérez Sánchez. Nada más inexacto. El dibujo fue puesto entonces a nombre de Cano por razones fundamentalmente estilísticas. No nos hemos movido en ese terreno y hemos obviado cualquier análisis sobre este punto. El trabajo está dedicado a estudiar los documentos relativos a la capilla de San Diego, y el dibujo ocupa una pequeña sección dentro de él. Con apoyo en documentos que asignan a Sebastián de Benavente toda su decoración y del convento, en

11 CRUZ YÁBAR, Juan María, "Pedro de la Torre y Francisco Bautista en el norte de España", Anales del Instituto de Estudios Madrileños, L (2010).

12 CRUZ YÁBAR, Juan María, "Sebastián de Benavente y la capilla de San Diego de Alcalá", Archivo Español de Arte, 324 (2008), p. 379-394.

13 BROWN, Jonathan, "Precisiones sobre la capilla de San Diego de Alcalá, en Santa María de Jesús de Alcalá de Henares", Archivo Español de Arte, 327 (2009), p. 316. 
el silencio de los biógrafos de Cano acerca de su participación en el retablo mayor -ni siquiera en su pintura-, en la realidad sociológica madrileña, y, sobre todo, en la estructura del retablo, hemos mantenido que el dibujo corresponde al mencionado maestro de arquitectura.

El estudioso ciñe sus comentarios a tres puntos o "cuestiones": La reproducción del dibujo no ha sido tomada directamente del original y, además, no muestra el zócalo. En nuestro descargo diremos que difícilmente podíamos localizar al innominado coleccionista florentino, citado como propietario hasta ahora por todos los autores que lo han hecho, incluso recientemente (Pérez Sánchez, 1988 ${ }^{14}$, Tovar Martín en $1990^{15}$, Rodríguez G. de Ceballos, 20016 ${ }^{16}$, Rodríguez Rebollo ese mismo año ${ }^{17}$, la propia Agulló en $2003^{18}$, etc). Celebramos conocer su paradero -que viene de muy atrás, al parecer- en la Morgan Library, pues, obviamente, no se había difundido entre los especialistas. Hubiéramos agradecido entonces una transcripción completa de la dirección de internet donde publican los datos y la atribución a Herrera Barnuevo, ya que, en el momento en que desveló estos datos Brown, no aparecía en la página web de la institución. En cuanto al recorte del zócalo, acháquese a los duendes de la imprenta, pues la imagen del catálogo de Zurbarán de 1988 de donde se mandó reproducir lo muestra completo, con los escudos, mencionados repetidamente en nuestro artículo al ligar el deseo de destacar el patrocinio real con el hecho de que estos adornos fueran desplazados luego al remate del retablo (p. 380 y 383).

La cuestión de la doble propuesta pictórica y escultórica es tratada con amplitud dentro de nuestro trabajo. No estamos conformes con el significado que atribuye Brown a este hecho. Hemos defendido que el dibujo era la traza originaria, modificada luego contractualmente, pero sin hacerse nuevo dibujo, salvo del tabernáculo y la urna. Es indiscutible que de ese original se hizo una copia, que quedó firmada en poder del convento franciscano, la cual tenía igualmente las dos propuestas, como consta claramente del contrato. Hemos establecido que el dibujo publicado por Pérez Sánchez fuera la traza que se quedó Benavente, que sería la más perfecta y acabada, y no estaría firmada.

Sorprenden dos afirmaciones de Brown: la primera, que Benavente no es demasiado conocido; diríamos que en ciertos ámbitos, porque la literatura sobre este arquitecto es abundante. En segundo lugar, que el dibujo sólo pudo, por su calidad excepcional y los efectos sutiles de la aguada, salir del pincel de un maestro dibujante. Los arquitectos de retablos eran maestros dibujantes, como demuestran sus contratos, en

14 PÉREZ SÁNCHEZ, Alfonso Emilio, “Capilla de San Diego, en el convento franciscano de Alcalá de Henares", en Zurbarán, Madrid, 1998, p. 331.

15 TOVAR MARTÍN, Virginia, "El ornamento barroco en el retablo-relicario para la urna de San Diego" en La Universidad de Alcalá de Henares, t. II, Madrid, 1990, p. 228.

${ }^{16}$ RODRÍGUEZ G. DE CEBALLOS, Alfonso, "Alonso Cano, arquitecto artista", Archivo Español de Arte, 296 (2001), p. 382; IDEM, "Dibujos canescos de arquitectura y decoración. Precisiones y comentarios de un catálogo reciente", en Simposium internacional. Alonso Cano y su época, Granada, 2002, p. 254.

17 RODRÍGUEZ REBOLLO, Ángel, "Una obra inédita de Alonso Cano en los fondos del Arzobispado de Madrid" en Simposium internacional. Alonso Cano y su época, Granada, 2002, p. 732

18 AGUlló Y COBO (2003), p 12. 
que siempre se alude a una traza, que en ocasiones se ha conservado, por lo que no se han de atribuir por sistema a los pintores los buenos dibujos de trazas arquitectónicas. Baste citar los diseños de Gómez de Mora para la fuente de la plaza de la Cebada y el retablo de Antón Martín, atribuidos antes a Cano por razones estilísticas, el de Alonso Carbonel de la Biblioteca Nacional, el mencionado de Francisco Bautista, los de Pedro de la Torre para el Ochavo de Toledo o los de los Churrigueras. Sebastián de Benavente, muy potente en lo económico y relacionado con los más importantes pintores de la corte, fue el maestro de una veintena de destacadísimos retablos de innovador diseño y no hay razón para que no se le pueda suponer dominio en el dibujo de trazas.

Brown anunciaba que el dibujo figuraría en una exposición de la Frick Collection, y efectivamente en el catálogo correspondiente es comentado en algunos aspectos por Banner ${ }^{19}$. No queremos detenernos sino brevemente en las líneas que ha dedicado esta autora, que ha calificado la atribución a Benavente de indefendible. Para sostener esta afirmación y rebatir nuestra argumentación, ha dado por sentado que hubo una primera traza de Cano, sin atender a las evidencias que hemos presentado señalando lo contrario, que no hubo más que una y de Benavente. Comenta que el dibujo tenía ya los cambios incorporados (suponemos que se refiere a los aludidos en el concierto de 29 de abril de 1658, lo cual es un contrasentido, pues si ya los tuviera el dibujo no se habrían advertido en la escritura) e imagina que uno de ellos fue la añadidura del friso decorativo central, eliminando así dos angelotes "tal vez procedentes de una idea anterior". En ninguna parte se señala que hubiera tal modificación, y obviamente la explicación de los piececitos que asoman es otra: simular la altura del camarín que queda oculta por el ático del retablo. Además, piensa que se trata de la traza que se presentó a Felipe IV por su esmerado acabado; por el contrario afirmamos que el monarca jamás se vio en la tesitura de tener que aprobar el proyecto, puesto que no se menciona en el contrato. Tampoco en ningún otro documento se especifica que algún diseño de los muchos que se hicieron precisara el beneplácito regio. Muestra del escaso seguimiento de las obras de la capilla por parte del rey es la ausencia de su representante en ellas, don Antonio de Contreras, en todos los contratos desde 16541655, en que se inició el patronato real, a excepción de la cantería de Lorenzo Pérez de Irias. El transcurso de las mismas se confió totalmente a los franciscanos y estos delegaron en fray Juan de San Francisco como sobrestante.

Por otro lado, queremos señalar al más que posible autor de las pinturas del retablo mayor. En nuestra opinión debió ser Antonio van de Pere, que hizo pinturas en otros retablos de Benavente, y precisamente en los franciscanos. Realizó en 1658 la pintura del camarín del mismo retablo de San Diego, y al año siguiente la orden exigió a Benavente su presencia en la pintura de los tres retablos de las capillas mayor y colaterales de San Antonio de Escalona. En 1663 era uno de los tres nombres propuestos por las claras de Madrid para hacer la pintura de su retablo, y Barcia ${ }^{20}$ publicó

19 VV.AA., The Spanish Manner. Drawings from Ribera to Goya, Nueva York, 2010, p. 43-46.

20 BARCIA Y PAVÓN, Ángel María., Catálogo de la colección de dibujos originales de la Biblioteca Nacional, Madrid, 1906, $\mathrm{n}^{\circ} 8.699$. 
un dibujo de la Biblioteca Nacional que Pérez Sánchez ${ }^{21}$ reconoció como suyo por la inscripción que lleva con su apellido. Su participación en las dos primeras obras constituye un indicio muy claro de que pintó los tres lienzos del retablo mayor de San Diego. De este modo cobran sentido los enigmáticos comentarios de Palomino respecto a las circunstancias en que Alonso Cano pintó en esa capilla. Dice el cordobés "También lo es otra de Nuestro Padre San Francisco en la Impresión de las Llagas en el Monte Alberne, que está en la Capilla de San Diego en Alcalá de Henares; y el San Antonio, que está enfrente, lo hizo también Alonso Cano; pero dizen, que no lo acabó, por las extravagancias de su genio; y por lo mismo dexó de hazer todas las demás Pinturas de aquella Santa Capilla, pues querían fuessen de su mano; y a la verdad lo huvieran acertado". El erudito conocía muy bien lo que hizo Cano en la capilla, es decir, los lienzos para dos de los retablos colaterales, e inventó -como suele ser habitual en él- un supuesto desencuentro para justificar que no hiciera los demás cuadros. La clave de esta cuestión la proporciona el último comentario, relativo al desacierto de los frailes por no haber podido contar con él. No supone tanto un elogio hacia Cano (la hechura por Zurbarán de los otros dos lienzos para los colaterales la desconocería), como un perjuicio para el otro pintor: van de Pere. Como puso de relieve la documentación hallada por Agulló ${ }^{22}$, Palomino tenía una franca animosidad contra el flamenco y también contra José García Hidalgo, pensamos que a raíz de alguna disputa por los contratos de la entrada de María Luisa de Orleans en 1679, en los que Palomino, recién llegado a Madrid, no consiguió entrar. Ni uno ni otro aparecen en su famoso tratado de la pintura, a pesar de haber tenido un papel de peso en el panorama pictórico cortesano. Lo lógico y acostumbrado además era que se empezara por los lienzos del retablo mayor y se siguiera por los de los colaterales y la pintura del camarín, concertada el 17 de julio de 1658, de modo que no tiene sentido que Cano hiciera primero dos colaterales y dejara el resto por hacer.

A la vista de la omnipresencia de Benavente como tracista en la capilla de San Diego es legítimo atribuirle otros diseños como la reja de entrada, hecha por Mateo Báez en 1658 "con balaustres maçorcados conforme a la muestra que se le diere"23, del escudo de armas reales de madera que tenía, y de la caja de órgano ${ }^{24}$. Benaven-

${ }^{21}$ PÉREZ SÁNCHEZ, Alfonso Emilio, “Antonio van de Pere”, Archivo Español de Arte, 156 (1966), p. 311-312. Este autor definió el asunto del dibujo como una alegoría de la Pobreza franciscana o de la Providencia veladora de la Orden. La forma de luneta y la presencia de panes y jarros que presentan los santos franciscanos, nos hace determinar el asunto como una alegoría de la Eucaristía que ofrece la orden a Cristo, redentor a través de su transubstanciación, un asunto muy indicado para la función del lienzo, sin duda destinado al refectorio de un convento franciscano. Este podía ser, a la luz de las intervenciones que conocemos de van de Pere, el de Escalona o el madrileño de Santa Clara. Descartamos el de Santa María de Jesús, porque, aunque tampoco se ha advertido, el cuadro del refectorio era sin duda y por su temática el de los Ángeles dando de comer a San Diego y sus compañeros de Ángelo Nardi (1640), desaparecido con el incendio del Archivo de Alcalá en la Guerra Civil.

${ }^{22}$ AGULLÓ Y COBO, Mercedes, "Noticias de arte en una información inédita de Palomino y Ruiz de la Iglesia", Archivo Español de Arte, 127 (1959), p. 240-241 y 245.

${ }^{23}$ AGULLÓ Y COBO (2003), p. 49.

${ }^{24}$ Atribuida erróneamente a Alonso Cano por TOVAR MARTÍN, Virginia, "El órgano de la capilla de San Diego de Alcalá de Henares. Aportación a la mecánica de la música en España" en La Universidad de Alcalá de Henares, t. II, Madrid, 1990, p. 260-262. 
te prestó además su fianza al platero Domingo Ruiz de Arbulu, que contrataba con el convento el 25 de agosto de 1658 la realización en bronce dorado de dos juegos de candeleros de seis piezas cada uno y otros doce relicarios, seis ochavados y seis ovalados $^{25}$. La fianza denota un interés de Benavente en estas obras de platería, y no solamente amistad con el platero. En el concierto se diferencia el diseño para la hechura de los candeleros, una tipo específico de la platería, del de los relicarios. Del primero se dice "la traça questá hecha y firmada del otorgante y del dicho padre fray Juan" y del segundo "conforme a las dos traças que se an hecho y están firmadas del otorgante y del dicho padre fray Juan de San Francisco". Obsérvese el diverso matiz entre ambas fórmulas; la primera aclara que fue Arbulu el tracista, y el impersonal de la segunda nos lleva sin duda a Benavente. También constatamos su intervención en el proyecto de ocho pirámides relicarios que hicieron para los nichos del crucero el ebanista Antonio Ontañón y el broncista Francisco Gutiérrez Zorrilla ${ }^{26}$ "conforme a una montea que al presente está hecha en una tabla".

\section{Retablo mayor y custodia del convento de Jesús y María de Valladolid}

Este retablo ha sido objeto de gran atención por parte de los eruditos antiguos y de los estudiosos contemporáneos. Palomino lo cita al respecto de las pinturas de Mateo Cerezo, que son las cinco que hoy se conservan enmarcadas en el retablo, además de un Salvador en la puerta de la custodia y cuatro cuadros más en el banco que no existen ya: San Pedro con su martirio al fondo, San Pablo con su conversión en segundo plano, San Antonio de Padua y San Francisco recibiendo los estigmas ${ }^{27}$. Coinciden con él en la descripción Ponz y Ceán Bermúdez. Pérez Villanueva ${ }^{28}$ localizó el contrato con el ensamblador vallisoletano Francisco Velázquez para hacer la labor de madera según la traza de Sebastián de Benavente. Buendía y Gutiérrez Pastor ${ }^{29}$ estudiaron las cinco pinturas principales.

En la actualidad, el retablo ha sido trasladado a un edificio moderno y el banco ha sido modificado, habiendo desaparecido sus cuatro pinturas, sustituidas por recuadros que imitan mármol jaspeado. El sotabanco o pedestal inferior, que era de recuadros moldurados semejantes a los del banco, es ahora un pequeño zócalo corrido. Estas modificaciones han alterado las proporciones generales con las que fue concebido.

${ }^{25}$ AGULLÓ Y COBO (2003), p. 59. Esta autora no transcribió completas las dos fórmulas relativas a las trazas.

${ }^{26}$ IBIDEM, p. 60.

27 «...Y en la puerta del Sagrario una hermosa efigie del Salvador y a un lado del Sagrario está San Pedro de cuerpo entero, y en lejos la historia de su martirio; y a el otro lado San Pablo, y a lo lejos su Conversión. Y en el banco de los pedestales está Nuestro Padre San Francisco en su Impresión de las Llagas y en correspondencia San Antonio de Padua y será cada pintura de éstas de tres cuartas de alto».

28 PÉREZ VILLANUEVA, Joaquín,»Unos lienzos de Mateo Cerezo en el convento de Jesús y María de Valladolid», Boletín del Seminario de Estudios de Arte y Arqueología, III (1934-1935), p. 346-350

${ }^{29}$ BUENDÍA, José Rogelio, y GUTIÉRREZ PASTOR, Ismael, Vida y obra del pintor Mateo Cerezo (1637-1666), Burgos, 1986, p. 34 y 112. 
Puede suponerse el motivo por el que don Ventura de Onís, miembro del consejo real y patrono del convento, que pidió las trazas a Benavente, decidió que el retablo se hiciera por un ensamblador vallisoletano. Un aparato de tal tamaño había de hacerse en un lugar inmediato a aquél en que se había de colocar, pues de otro modo, los gastos del transporte hubieran encarecido considerablemente la obra. Benavente trazaría el retablo poco antes de celebrarse el contrato con el maestro que lo iba a ejecutar, que lleva fecha de 29 de abril de 1658. En aquellos momentos, no podía trasladarse a Valladolid, porque se encontraba haciendo -entre otros encargos menos importantes- los retablos de San Diego de Alcalá, que eran obra patrocinada por el rey.

Las condiciones para la hechura fueron seguramente redactadas por Francisco Velázquez, ya que aparecen firmadas por él y por don Ambrosio de Onís, hijo del comitente y regidor de la ciudad, que firma también el contrato. Son muy ricas en detalles, e incluso introducen alguna modificación respecto a la traza, quizá por consejo del propio Velázquez.

En las obligaciones del vallisoletano no entraban el dorado y estofado del retablo ni las pinturas de Cerezo, que pagaría el comitente aparte. Tampoco corría de su cuenta el pedestal, que expresamente se pone a cargo del patrono. No se describe el tabernáculo, pero se dice que estaba a cargo de Velázquez hacerlo según mostraba la traza, si acaso un poco más pequeño, unos seis pies de alto. Debía llegar hasta los pies de las efigies de María y Jesús del hueco central, y las condiciones indican que el pedestal de estas imágenes llevaría una tarja en relieve, que no aparecía en la traza por taparlo la custodia.

El retablo se compone de dos cuerpos. El centro del inferior está ocupado por una gran caja central de seis pies de profundidad donde se aloja el grupo de Jesús y María, advocación del convento, colocado sobre la peana aludida anteriormente. El nicho, acabado en medio punto, se enmarca con una línea quebrada de tarjas de medio relieve que forma un gran recodo arriba, donde se situaba un cogollo de hojas carnosas en relieve. Los laterales del cuerpo inferior llevan a cada lado dos columnas estriadas dobladas por pilastras, todas con capiteles corintios, y en los intercolumnios dos marcos de hojas talladas y con contornos semejantes a los del nicho central, donde se sitúan las pinturas de Cerezo de la Adoración de los pastores y la Adoración de los Magos; en su parte superior llevan también tarjetas carnosas. Las columnas de los extremos son robadas. El cornisamento que separa el cuerpo principal del superior coincidía con la cornisa de la capilla, y está formado por un friso que alterna cartelas sobresalientes y cogollos en las metopas. En la parte correspondiente a las columnas, el friso forma una especie de capitel que dobla al de la propia columna y que surge a partir de su propio desarrollo decorativo.

El cuerpo superior del retablo tiene forma de semicírculo. Se inicia con un zócalo de media vara sobre la cornisa, apenas decorado. Encima de las columnas surgen dos machones lisos con la parte delantera cajeada y rematados en una pequeña ménsula a cuyos lados cuelgan racimos. Entre los dos machones se encuentra un recuadro con un marco de molduras y tarjas parecido al del cuerpo inferior, con contorno quebrado formando un seno superior donde se aloja una gran tarja. El hueco central lo ocupa la Asunción. Para el contorno del cuadro, Francisco Velázquez debió de aconsejar una simplificación de la traza, ya que las condiciones dicen: "adviértase que no a de llebar 
el codillo que tiene los dos largueros que suben de pie derecho, por causa que hace feo...". Esos largueros que se suprimen son sin duda unas orejetas que formarían los extremos superiores del tarjetón semejantes a las que existen sobre el nicho de la parte inferior. Velázquez aligeró el diseño y lo redujo a dos apéndices de remate mucho más simples. A los lados exteriores de los machones, en las enjutas del arco, se sitúan otros marcos -los de las pinturas de San Buenaventura y Santa Isabel de Hungría, santos patrones de don Ventura y de su mujer doña Isabel de Cotillón- cuyos contornos, también rodeados de un marco de tarjas de medio relieve, siguen por el lado exterior la línea semicircular del remate. El borde externo del cuerpo superior está formado por un gran marco moldurado, llevando una de estas molduras un adorno de tarjas carnosas. Los machones rematan en un recorte de cornisa volada con dentellones en la parte inferior. Encima de ellos se encuentran dos alegorías, la $\mathrm{Fe}$ con cáliz y la Esperanza con ancla; podrían tener origen en una mejora respecto al contrato, donde no hay alusiones a ellas.

Don Ventura de Onís eligió un ensamblador con muy buen oficio, que realizó la obra con toda corrección. Su precio, 11.500 reales, fue inferior al que hubiera costado hacer en Madrid un retablo equivalente. Las dos esculturas centrales estaban a cargo de Velázquez, pero se había de realizar por Juan Rodríguez.

El plazo para acabar el retablo se fijó en año y medio a partir de la fecha de la escritura, lo que quiere decir que tuvo que haberse terminado, si Velázquez cumplió, antes de fin de octubre de 1659. Nada se indica acerca del dorado, ni se han encontrado escrituras de contrato con el pintor de los cuadros, Mateo Cerezo, cuya autoría no es dudosa porque firma dos de ellos con su nombre -Adoración de los pastores y Asunción- y el último lo fecha en 1659. Cerezo era un pintor burgalés muy joven -entonces tenía 21 años- pero excelente, y estaría dispuesto a viajar a Valladolid para ocuparse de lo relativo a la pintura de ese retablo. Ese viaje no hubiera sido imprescindible si sólo se hubiera ocupado de la pintura de los lienzos, por lo que es posible que Cerezo viajara para cuidar de que el dorado se hiciera con la perfección debida. En octubre de 1658 estaba en Valladolid, ya que mantuvo un pleito por haber matado a cuchilladas la mula que le llevó desde Madrid. Buendía y Gutiérrez Pastor le suponen residiendo allí buena parte de 1659, lo que haría coincidir su estancia con el tiempo en que los doradores estaban realizando su labor, hasta fines de ese año en que el retablo estaría acabado y asentado. No se sabe exactamente en qué fecha marchó a su Burgos natal, aunque hay certeza de que estuvo allí en 1660. Todos estos datos podrían confirmar que su estancia en Valladolid tuvo relación directa con este retablo.

Este retablo de Sebastián de Benavente y el de San Diego nos permiten conocer los logros alcanzados durante un lustro, desde el de la Puebla de Montalbán. Su estilo se caracteriza por un perfecto equilibrio entre la unidad de los elementos arquitectónicos y el despliegue de los recursos ornamentales, ya apuntado en el retablo toledano. Así consigue un resultado de gran riqueza visual y efectismo, pese a ser mucho más parco que otros ensambladores madrileños en la utilización de recursos de claroscuro, que encarecían la obra sin conseguir mejores logros estéticos. Destacan los codillos de complejos perfiles, originalmente pronunciados en sus extremos para acoger las tarjetas, que muestran un elegante y desarrollado diseño. En la tarjeta superior hay festones con frutos, un recurso decorativo que aparece ya en las del 
intercolumnio de la epístola e incluso en los capiteles de San Diego, que se adornan con esos mismos frutos.

\section{Retablo mayor y custodia, dos colaterales y librería del convento de San Antonio de Escalona}

El marqués del Saltillo dio a conocer y transcribió los fragmentos más importantes del concierto que celebró Sebastián de Benavente con los doradores y estofadores del retablo mayor y los colaterales para el convento de San Antonio de Escalona, que él había contratado. Agulló proporcionó la referencia de los protocolos en que se encontraban los contratos que hizo el ensamblador con el convento, sin entrar en detalles. Buendía y Gutiérrez Pastor se refirieron a esta obra comentando la participación de van de Pere en la hechura de los lienzos. Los retablos desaparecieron a raíz de la desamortización, sin que se conozca la subsistencia de ningún resto. Tampoco conocemos ninguna estampa.

El encargo del retablo mayor llegó para Benavente tras terminar el retablo de San Diego; los responsables de la orden quedaron muy satisfechos no sólo del ensamblador, sino también de Antonio van de Pere, y del estofador, Antonio Brustín, cuya intervención exigieron en la pintura y el estofado.

El 1 de noviembre de 1659 Benavente y el padre Felipe de la Torre, presidente perpetuo de la provincia de Castilla, otorgaron concierto para la hechura del retablo mayor $^{30}$, que había de dar terminado a fin de mayo de 1661, año y medio después. Se estipulaba un precio alto, 4.000 ducados, equivalentes a 44.000 reales como en La Puebla y Alcalá, si bien se ha de tener en cuenta que el dorado y la pintura corrían por su cuenta. Apenas tres meses más tarde, el 20 de febrero de 1660, recibía el encargo de hacer dos colaterales por precio de 21.000 reales, incluyendo pintura y dorado igualmente ${ }^{31}$. Tres días después celebraba Benavente contrato con el dorador Melchor de Viveros y Brustín, conviniendo en pagarles 16.500 reales por su labor en el retablo y custodia del altar mayor y los dos colaterales ${ }^{32}$. El 27 de octubre de 1661, Benavente otorgaba finiquito por la obra de Escalona a favor del síndico Francisco del Yermo, que había actuado como pagador, por la cantidad de 68.140 reales $^{33}$. De ellos, 65.000 correspondían a los tres retablos según lo estipulado en el contrato, 2.000 reales más por demasías -quizá dos pequeñas custodias para los colaterales de las que no se habla en el contrato pero sí en el finiquito- y 1.140 reales más por unos estantes que había fabricado para la biblioteca del convento. De este modo, si deducimos lo que cobraron los doradores -quizá algo más de lo estipulado, pues los pequeños sagrarios tampoco estaban comprendidos en su contrato- y lo que pudo cobrar Antonio van de Pere por las nueve pinturas que llevaba el retablo mayor y las dos

${ }^{30}$ AGULLÓ Y COBO (1978), p. 21-22.

${ }^{31}$ IBIDEM, p. 22-23.

32 SALTILLO, Marqués del, «Artistas madrileños», Boletín de la Sociedad Española de Excursiones, LVII (1953), p. 155-156.

33 AGULLÓ Y COBO (1978), p. 24. 
de los colaterales también suyas, cantidad que podemos cifrar en unos 5.000 ó 6.000 reales, resta como pago del ensamblador unos 40.000 ó 41.000 reales. Esta cifra nos lleva a pensar que el retablo mayor era de gran tamaño y con labores complicadas, y los colaterales en proporción.

El retablo mayor no se describe apenas en el contrato con Benavente, ya que se había de hacer sobre su propia traza y a ella se remiten las partes; tan solo consta que llevaba nueve pinturas, dos de gran tamaño en los laterales del cuerpo del altar de los santos Bernardino y Buenaventura. La referencia al altar a esta altura parece indicar que el banco era muy pequeño, y que el cuerpo principal apoyaba directamente sobre el zócalo. Si en lo que constituía el primer cuerpo se mencionan dos pinturas laterales sin que se haga referencia a ninguna pintura central ni a su asunto, podemos suponer que era porque allí se situaba un gran nicho con una talla de San Antonio, que era el titular del convento. La altura que presuntamente alcanzaría la custodia, por lo que luego explicaremos, obligaría a elevar la imagen sobre una peana. El hecho de que la custodia hubiera de separarse del retablo dejando por detrás un pasillo sugiere la existencia de algún camarín colocado detrás del altar y debajo de la hornacina central.

La forma en que se repartían las siete pinturas restantes es una incógnita, pero podemos suponer que en el cuerpo superior, en las enjutas, irían dos de forma irregular y una más en el centro, rectangular o casi cuadrada. En el cuerpo principal podían situarse quizá dos pinturas pequeñas, de formato casi cuadrado, encima de los dos santos laterales, y las otras dos en el banco, aunque no hay que descartar que en ese lugar se colocaran adornos de talla y no pinturas, en cuyo caso, las cuatro pinturas restantes ocuparían los vaciados de los pedestales de las columnas, que no dudamos que existían en número de cuatro, dado el tamaño del retablo y la fecha relativamente temprana en que se hace la obra. La custodia había de llevar transparencias en sus cuatro puertas, lo que seguramente implicaba otras cuatro pinturas en puertecillas que podían ser retiradas por algún mecanismo para la exposición del Santísimo.

El documento se hace más explícito al mencionar la forma de remate de la custodia. Encima de su cúpula se haría un pedestal en forma de arca, a modo de trono, para colocar sobre él una imagen de la Virgen, Nuestra Señora de los descalzos, sin duda de pequeño tamaño, que se veneraba en el convento desde el momento de su fundación, puesto que había sido puesto originariamente bajo su advocación.

El contrato para la hechura de los colaterales no ofrece tampoco demasiados detalles. Se especifica que las columnas tenían que ser estriadas, lo que hace suponer que Benavente no había especificado la decoración de los fustes. El cuerpo central estaba ocupado por una hornacina donde se situarían las imágenes titulares de los respectivos altares: en el retablo del lado de la epístola, una escultura de la Inmaculada Concepción que se hallaba en el coro, y en el lado del evangelio, la imagen de San Francisco que el padre Felipe de la Torre mandaría hacer por cuenta del convento. La dedicación del primero de estos altares varió posteriormente, pues el finiquito de octubre de 1661 menciona que los colaterales eran de San Francisco y de San Diego. La parte superior de los retablos tenía en su centro una pintura relacionada con las respectivas dedicaciones, de los Desposorios en el retablo de la Inmaculada y de un milagro de San Francisco -la Estigmatización, el episodio de la zarza, la Porciúncula o el concierto de los ángeles-, ambas de mano de van de Pere como exigía el contra- 
to. Es de suponer que, al cambiar la dedicación del primero de los altares, su asunto definitivo fue seguramente el milagro de las rosas de san Diego de Alcalá.

Puede resultar extraño a los ojos actuales que los franciscanos se encontraran más satisfechos de la obra de van de Pere en la capilla de San Diego que de la de Cano o Zurbarán, que también habían trabajado para ella. Posiblemente influyó en las preferencias el precio de estos pintores, que sería inasequible para la obra de Escalona, teniendo en cuenta el gran número de pinturas que llevaban y que estos retablos se habían de pagar de limosnas, sin ayuda real como la que había gozado el convento de Alcalá.

Es peculiar la forma en que se conviene el pago al contratista de la obra, aunque tampoco resulta raro a la vista de otros casos que se conocen de pago mediante limosnas de los devotos. A la firma del contrato recibió unas cantidades relativamente elevadas, 5.500 reales en el caso del retablo mayor y 2.750 reales en el de los colaterales. Durante los doce meses siguientes, al comienzo de cada mes, se le darían 1.200 reales por el retablo mayor y acabadas estas mensualidades, 1.000 reales durante seis meses más, en total 20.400 reales; por los colaterales se produjeron pagos equivalentes, de 600 reales al mes durante doce meses y posteriormente cuatro meses más a 800 reales, en total, 10.400 reales. En 15 de julio y 1 de noviembre de 1660, respectivamente, $\mathrm{o}$ antes si fuera necesario, coincidiendo con la fecha prevista para los primeros pagos a doradores y pintores de los tres retablos, percibiría Benavente otras cantidades relativamente elevadas, 11.000 reales por el mayor y 5.500 por los colaterales. Su suma coincide exactamente con el precio convenido con los doradores en el contrato de 23 de febrero de 1660, 16.500 reales. El resto hasta completar el precio, 7.100 reales en el mayor y 2.350 reales en los colaterales, al finiquito de los contratos.

La incertidumbre de que los futuros pagos se fueran haciendo con regularidad y en sus plazos debió de llevar a los contratantes a introducir una fórmula por la que Benavente quedaba liberado de seguir con su fabricación si aquéllos no se cumplían. No obstante, habiéndose pagado dos terceras partes del precio total, se obligaba a pasar por una tasación que estableciera si había realizado o no la obra correspondiente a esos pagos, $\mathrm{y}$, no habiéndolo hecho, podría ser apremiado a cumplir hasta ese precio.

La conclusión de los retablos debió incluso avanzar respecto de lo previsto en los contratos, fin de mayo de 1661 el mayor y fin de junio de ese año los colaterales. Los adelantos se aprecian ya en la fase intermedia, porque Benavente convino con los doradores que la primera paga de 5.500 reales se les haría el día 1 de junio de 1660 , momento en que esperaba poder entregarles ya las primeras piezas para dorar, no obstante que el contrato con el convento establecía que se le darían los primeros 11.000 reales para el dorado el 15 de julio.

La rapidez en la ejecución parece confirmarse por el finiquito de los pagos de la obra que otorga Benavente el 27 de octubre de 1661. Teniendo en cuenta que los contratos con el convento imponían una garantía del ensamblador de sustituir o solucionar los defectos que pudieran ponerse de manifiesto en la madera en los seis meses siguientes a la colocación definitiva de los retablos en sus asentamientos, suponemos que el convento retuvo la última paga hasta que hubo transcurrido ese plazo, lo que nos sitúa a fines del mes de abril de 1661 como fecha casi segura fecha de terminación de los retablos. 
El retablo mayor muestra una disposición parecida al de La Puebla de Montalbán en cuanto a la disposición de la imaginería; la iconografía es un muestrario de santos franciscanos -incluidos los colaterales- como el del dibujo de van de Pere preparatorio tal vez para el lienzo del refectorio de este convento.

\section{Portada de la iglesia del convento de Santa María de Jesús en Alcalá de Henares}

Barrio Moya dio noticia del contrato de 5 de julio de 1662 por el que los maestros marmolistas Miguel y Pedro de Tapia y Miguel Sombigo concertaron la hechura de la portada del convento complutense. No dudó en establecer la autoría de Sebastián de Benavente en la traza a partir de dos cláusulas que señalaban su potestad para modificarlas si lo consideraba preciso ${ }^{34}$. Agulló mostró algunas reservas respecto a esa autoría, que desde luego nosotros no tenemos, a la vista de la trayectoria de Benavente en el convento y porque la facultad de modificar trazas estaba reservada al autor del proyecto salvo excepciones muy contadas. Se dice además que "la traça estaba hecha y dibujada, y queda firmada del Mui Reverendíssimo Padre Comissario General de Jerusalén y de los dichos otorgantes y su fiador y de mi, el escribano". Nuevamente se diferencia la hechura de la traza de la firma del comitente y los otorgantes. Era habitual que los arquitectos de retablos diseñaran portadas, porque no tenían problemas constructivos que no pudieran resolver unas condiciones redactadas por los maestros de obras, y la importancia residía en la ornamentación, para lo que estaban mejor capacitados aquéllos que estos.

La reina Mariana de Austria destinó más de 100.000 reales para su hechura. Era de piedra berroqueña, con gradas de acceso a la entrada, en cuyo remate había una tarjeta con la inscripción Santa María de Jesús. En este primer cuerpo había cuatro pilastras dóricas que sostenían un entablamento, y en las entrecalles hornacinas con los Santos Francisco y Antonio, de seis pies de alto, piedra berroqueña y cabezas y manos de mármol blanco de Génova. Del mismo material era la Virgen del segundo cuerpo, de medio relieve y con peana de piedra berroqueña y trono de serafines de mármol. Estaba colocada en un nicho entre dobles machones con friso y cornisa encima, de donde salían unos aletones acabados en pirámides con bolas. Seguía un tercer cuerpo que enmarcaba la ventana con codillos, jarrones y machones, y un frontispicio con el escudo de armas reales de piedra de Colmenar con sus adornos y remates. Román Pastor reconstruyó la imagen de la portada con bastante corrección, excepto en el segundo cuerpo, en que sólo hay dos machones, ausentes totalmente en el tercer cuerpo, y en la forma de algunos adornos. Se trata de la única incursión que se conoce por el momento de Benavente en este campo, y si bien la estructura es tradicional, donde destaca su diseño es en la profusión decorativa, con elementos típicos como pirámides o bolas, pero también otros poco usuales como tarjetas, codillos, jarrones y machones con vaciados, que provienen del ámbito del retablo de este momento.

34 BARRIO MOYA, J. L., "El arquitecto Sebastián de Benavente y la desaparecida portada de la iglesia del convento de San Diego de Alcalá“, Anales complutenses 2 (1988), p. 21-29. 


\section{Retablo mayor y custodia del convento de Santa Clara en Madrid}

Del retablo de la iglesia de este convento madrileño de Santa Clara no ha quedado ningún testimonio materia ${ }^{35}$. Por fortuna hemos hallado el concierto de Benavente con el convento ${ }^{36}$, que al ser bastante explícito permite reconstruir la forma que tenía. El 19 de octubre de 1663 comparecieron ante escribano las clarisas y el arquitecto para determinar los términos por los que haría el retablo de la iglesia, que se renovaba para mayor decencia en la celebración de los oficios divinos. La traza estaba hecha por Benavente, firmada de su mano y del padre provincial, vicario y mayordomo del convento, y del escribano. Tenía que hacerlo con muy buenos ensamblajes, con la custodia que mostraba la traza, en la cual se habían de poner puertas que se ocultaran mediante torno para descubrir en las fiestas el Santísimo Sacramento. Éste se custodiaría en una caja, que iría en el pedestal.

En el banco del retablo tenía que hacer Benavente adornos de frutero. Las columnas serían estriadas y los capiteles de hojas arpadas. Los cuadros principal y de remate se harían de tarjetas, y en las entrecalles iban tarjas, fruteros y cuadros tallados para el lienzo de cada entrecalle. El entablamento llevaba adornos tallados y una tarjeta en medio adornando el cuadro. El remate del cerramiento era de talla y tenía otra tarjeta.

El retablo y la custodia tenían que dorarse con oro de muy buen color del que batía Manuel Martín, y debía aparejarse para dorar la talla y colorearla, dar barniz para que no se oscureciera, y hacer de grafío las labores que mejor pareciere. También había que hacer un zócalo de piedra berroqueña como el que mostraba la traza, que tenía que ser de alto como el altar. Finalmente quedaban a cargo de Benavente también los lienzos de pintura que mostraba la traza, que serían de mano de Francisco Camilo, Antonio van de Pere o Francisco Ginés, según la elección del arquitecto y a satisfacción de la abadesa y del padre fray Pedro Sedeño y Juan de Baroja, vicario y mayordomo del convento respectivamente, o los que lo fuesen en el futuro.

Benavente disponía de un año y medio desde la fecha de la escritura para dar acabado y asentado el retablo en toda perfección y con aprobación del convento. Benavente dio por su fiador a Juan Bautista Zabala, el mismo mercader que le fió diez años antes para La Puebla. Recibiría 30.000 reales por hechura y materiales, con 3.000 de contado, 5.000 para fin de febrero de 1664, otros tantos para fin de junio, 4.000 a fines de octubre, la misma cantidad al terminar febrero de 1665, 5.000 al finalizar junio y los 4.000 restantes al acabar y asentar el retablo. El tiempo previsto era en realidad de un año y casi nueve meses, sin contar el último plazo.

Agulló publicó el documento del contrato de Benavente con los doradores y estofadores Toribio Gómez y Francisco Guillén Brito, que se hizo el 21 de enero de $1666^{37}$, seguramente poco después de acabar el arquitecto. En esta ocasión se haría el trabajo en un período de cinco meses, hasta finales del mes de junio de ese mismo año, por un precio total de 8.500 reales: 2.000 en el acto, otros tantos los últimos

${ }^{35}$ Quedan dos grabados en el Museo de Historia de Madrid que muestran la imaginería de la calle central, si es que es de tiempos de Benavente: en el cuerpo principal una Piedad de escultura, y el lienzo de la Apoteosis de Santa Clara en el superior.

${ }^{36}$ Archivo Histórico de Protocolos de Madrid, prot. 8.722, fol. 888-892v.

37 AGUlLó Y COBO (1978), p. 25. 
días de marzo, sendos pagos de 1.000 reales a fines de abril y mayo respectivamente, 1.000 al acabar y los 1.500 restantes tras su asiento. Gómez y Guillén Brito firmaron el finiquito con Benavente el 4 de noviembre de 1666, lo que supone un retraso de cuatro meses.

De este concierto no se puede extraer prácticamente ningún dato, salvo de nuevo que las trazas fueron de Benavente, que contrató por su cuenta a los doradores como se había pactado. La parquedad de exigencias y datos refleja la confianza que había entre ambas partes, nacida probablemente de la mutua colaboración entre Benavente y Toribio Gómez en los retablos de Santa Isabel de Madrid. El retablo era de tamaño medio grande; de los 22.500 reales que quedan una vez descontado el dorado, serían algo más de 18.000 para el ensamblaje y el resto para la pintura.

La apariencia del retablo era aún similar a los de los años cincuentas, pero sólo en la estructura, con festones en el banco, columnas estriadas con capiteles de hojas arpadas, marcos de tarjetas, fruteros y tarjas adornando las entrecalles, pinturas en ellas y en el remate -probablemente también en el centro del cuerpo principal-, entablamento adornado de talla como el cerchón de cerramiento, y dos tarjetas sobre los cuadros central y de remate. Sin embargo, la diferencia estaría ya en la ornamentación, que sería más frondosa y más arpada en las tarjetas, fruteros y marcos.

\section{Retablo mayor del convento de Santa María de Jesús en Alcalá de Henares (hipótesis)}

Unas cuentas que mantuvo Benavente con dos síndicos generales de la orden franciscana, Lucas Ezquerra y Juan Lázaro de Ledesma, mercaderes de paños asociados hasta 1665 y ligados a las obras en el convento de Santa María de Jesús, y algún otro dato, abren la posibilidad de que hiciera el retablo de este templo. Ezquerra representó al convento de Santa María de Jesús en la renuncia que hizo Ana de Llamas en 1648 del patronato de la capilla de San Diego, y fue consultado por fray Juan de San Francisco sobre la continuación de las obras de albañilería en 1653. Ledesma aparece en 1663 relacionado con la obra de la portada complutense. El 16 de abril de 1665 concedió Benavente espera de cinco años a Ezquerra por una deuda de 3.643 reales. El arquitecto otorgó carta de pago a favor de ambos mercaderes el 28 de mayo de 1666 por 3.748 reales. Había cobrado 1.269 reales de mano de Ezquerra, y el resto, 2.479 reales, los percibió Benavente de un tal Diego de Bocaya. El 30 de junio de ese año otorgó nueva carta de pago por 4.605 reales de Ezquerra. No deben ser estos importes por las obras de San Diego debido a la distancia cronológica, ni de la traza de la portada por ser muy elevada la cantidad (prácticamente 12.000 reales). La opción más válida es la del retablo mayor de Santa María de Jesús, que tendría en el centro esta antigua imagen destruida en 1936 pero conocida por fotografía, y con camarín que cita Ponz. 


\section{Retablo mayor y tabernáculo de Santa Juana de la Cruz en el convento de Santa María de la Cruz de Cubas de la Sagra (atribución)}

Es muy probable que Benavente trazara la urna de jaspes y mármoles que se hizo para contener los restos de Santa Juana de la Cruz en Cubas, y también el retablo. Esta actuación se ha de inscribir en un contexto más amplio de la reforma completa de una capilla devocional donde se venerarían los restos de la sierva de Dios que vivió en aquel convento, cuya pronta ascensión a los altares parecía segura en aquellos momentos, aunque luego no se consiguió. El 7 de septiembre de 1666 se encargó a Bartolomé Sombigo la construcción de un gran tabernáculo exento ${ }^{38}$, con cuatro cuerpos en mármoles y jaspes y cuatro fachadas con sus respectivos altares, dos sagrarios, uno hacia la nave de la iglesia y otro hacia el testero de la capilla, incluyendo este último una gran cornisa encima del sagrario para poder colocar el Santísimo, sin duda porque el retablo no llevaría altar, sino que en su zócalo se abriría la ventana del coro de las monjas. En el interior del tabernáculo se colocaría una urna con los restos de sor Juana. Se habla de una traza que está "hecha y dibuxada", firmada por los otorgantes y a la cual Sombigo no podía añadir nada.

Sospechamos que fue Benavente el tracista por varios motivos. En primer lugar, el responsable de las obras del convento en este momento, fray Juan de San Francisco, era el mismo del convento de San Diego, en el que Benavente dejó muchas obras excelentes. Los artífices de ambas obras están también relacionados, como el propio Sombigo, hermano de Juan, uno de los dos marmolistas que contrataron la urna de mármoles y jaspes de San Diego, y de Miguel, que trabajó con los Tapia en la portada de Santa María de Jesús. Otro era el maestro de obras Manuel García, que contrató el 6 de mayo de 1666, entre otras cosas, la construcción de una media naranja y chapitel sobre el crucero de la iglesia, y la apertura de un camarín para el retablo mayor ${ }^{39}$. Este maestro era hermano de Juan García, autor del revoco de la sacristía de las clarisas alcalaínas $^{40}$, la albañilería de la capilla de San Diego, y de los coros de la iglesia de Santa María de Jesús. El dorador del retablo de San Diego, Clemente de Ávila, repitió también, en esta ocasión para encarnar y estofar las esculturas que le daría Pedro Alonso de los Ríos, al cual fió. Seguramente eran para el retablo mayor de la iglesia, cuyo dorado habría hecho el propio Ávila. El concierto de ambos con fray Juan de San Francisco se llevó a cabo el 15 de febrero de 1667, e incluso en este caso en que el maestro escultor no tuvo relación con la capilla de San Diego, la iconografía de las tallas llevan al retablo complutense. Los tres santos son los mismos, si bien hechos de escultura y no de pintura, según la disposición de la epístola del dibujo de la Morgan Library. La emulación es incluso algo forzada, pues si bien se representa a San Antonio habitualmente con el Niño, no así a San Francisco. Tampoco parece

38 AGULLÓ Y COBO, Mercedes, "Pedro, José, Francisco y Jusepe de la Torre, arquitectos de retablos" Anales del Instituto de Estudios Madrileños, XXXVII (1997), p. 37. De nuevo se interrumpe la transcripción en la fórmula relativa a las trazas.

${ }^{39}$ BARRIO MOYA, José Luis, "El arquitecto Manuel García y el escultor Pedro Alonso de los Ríos en el convento de Nuestra Señora de la Cruz en Cubas de la Sagra", Boletín del Seminario de Estudios de Arte y Arqueología, XLVIII (1982), p. 440.

${ }^{40}$ ROMÁN PASTOR, op. cit., p. 198. Manuel García tasó además el claustro en 1670. 
haber un motivo firme para la presencia de San Diego en el ático. Aparece también en el milagro de las rosas y con cruz, por la advocación del convento y la devoción de la venerable a la misma. Se harían conforme a unos modelos señalados y plantados en la iglesia ${ }^{41}$, seguramente de Benavente. Los otros ocho eran ángeles, como en San Diego, de vara y tercia de alto cada uno, huecos para pesar poco. Irían en torno al camarín y simularían que bajaban del cielo hacia la imagen de la virgen titular del convento -santa María de la Cruz- con rosarios en las manos. La devoción popular atribuía a las cuentas del rosario de santa Juana propiedades curativas.

\section{Retablo de la capilla de Nuestra Señora de la Esperanza en Santa Clara de Al- calá de Henares}

Román Pastor ${ }^{42}$ dio noticia de un pago a Benavente hecho por la abadesa de este convento, Inés de San Vicente, por el retablo para la capilla de la Virgen de la Esperanza. El recinto se conocía popularmente por esa advocación. La capilla estaba situada junto a la mayor en el lado del evangelio. No era mucha la cantidad, 3.500 reales, por lo que se trataría de un pago parcial. Benavente firmó el recibo en Alcalá el 26 de octubre de 1667; pensamos que alguna circunstancia de mayor peso le detenía en Alcalá. Sólo sabemos del retablo que tendría una hornacina central con la imagen de la Virgen, que sería antigua, y tendría por tanto camarín.

\section{Apéndice documental}

Archivo Histórico de Protocolos de Madrid, prot. 8.722, fol. 888-892v.

El convento de Santa Clara y Sebastián de Venabente concierto sobre un retablo. 19 ottubre.

Estando en el convento de monjas de Santa Clara, orden de nuestro padre San Francisco, desta villa de Madrid, a diez y nuebe días del mes de otubre, año de mill y seiscientos y sesenta y tres, ante mi el scrivano del número y testigos ynfraescriptos, parecieron las señoras abadesa, vicaria y discretas del dicho convento, que se juntaron en un locutorio del por la parte de la clausura, especial- y señaladamente doña Ana de Murias y Valdés, abadesa, doña Ana Tello, doña Cattalina de Prado, doña Juana de Montoya, vicaria, doña Beatriz Cercito, doña Jacinta de Reynoso, doña María Pichón, doña Lucrecia de Salinas, sor Luisa de la Paz, discretas consiliarias que hacen convento pleno, y a mayor abundamiento prestaron voz y caución en forma por las demás relijiossas que dél son y fuesen, para que estarán y passarán por lo que en esta escriptura se a convenido, y no yrán contra ello en tiempo ni manera alguna, so espressa obligación que hicieron de los vienes y rentas del dicho convento, espirituales y temporales havidos y por haver, y ansí juntas y congregadas de una parte, y de otra Sebastián de Venabente, maestro de arquitetura, vecino desta villa, y las dichas señoras abadesa,

\footnotetext{
41 BARRIO MOYA, p. 440.

42 ROMÁN PASTOR, op. cit., p. 188.
} 
vicaria y discretas, usando de la licencia y patente que para el otorgamiento desta escriptura tienen del muy reberendo padre fray Alonso de Salaçar, calificador del consejo supremo de la jeneral Inquisición, vicario probincial de esta santa probincia de Castilla de la dicha orden, su lixítimo prelado que está firmada de su mano, y se le da con efecto mayor de su oficio y refrendada del padre fray Gerónimo del Canto, su scribano, su data en el convento de San Francisco desta villa de Madrid en quatro deste presente mes de otubre, que su thenor es como se sigue: -Aquí la licencia y patente-.

Y usando de la dicha licencia y patente las dichas señoras abadesa, vicaria y discretas y el dicho Sebastián de Venabente, dada para por lo que les toca dijeron que en raçón del retablo que se a de hacer para el altar mayor de la yglesia del dicho convento de Santa Clara, de que se ba encargando el dicho Sebastián de Venavente, para que con mayor decencia se celebren los oficios divinos, se an conbenido y concertado y por la presente se conbienen y conciertan en esta manera:

-El dicho Sebastián de Venabente se encarga de hacer el dicho retablo en conformidad de la traça que para ello está echa y firmada de su mano y del dicho padre provincial vicario y mayordomo del dicho conbento y de mi el presente scrivano.

-Que el dicho retablo se ha de hacer de madera de pino de Balsaín seca y limpia de ñudos con muy buenos ensanblaxes en todas las partes que conbengan para su duración.

-Que ansimismo se a de hacer la custodia que muestra la traça con muy buenos ensanblaxes, en la qual se an de hacer puertas que se oculten para descubrir el Santísimo Sacramento en las festibidades, haciendo torno para ello.

-En el pedrestal de la custodia se ha de hacer caxa como muestra la traça para que esté colocado el Santísimo Sacramento.

-En el predestal del retablo se an de hacer los adornos de fruteros que muestra la traça y las colunas an de ser estriadas derechas y los capiteles de ojas arpadas y los quadros principal y del remate se an de hacer de tarxetas según la traça, y en las entrecalles del dicho retablo se an de hacer las tarxetas y fruteros que dice la traça y se ha de tallar el quadro que guarnece el lienço de cada entrecalle, y se an de hacer los adornos de talla que muestra la cornissa, con la tarjeta que viene en medio adornando el quadro.

-Ansimismo se a de hacer la talla que muestra el remate del cerramiento con su tarjeta como lo muestra la traza.

-Que todo el dicho retablo se ha de dorar con oro de muy buen color de lo que bate Manuel Martín, batidor de oro, en esta corte, y todo el dicho retablo y custodia que muestra la traza se ha de aparexar para dorar de aparejo que más conbenga para su duración, y ansimismo se ha de dorar toda la talla y colorirla con muy buenas colores, y barneçerlas para que no se oscurezcan, y hacer de grafio las labores que mejor parezcan.

-Ansimismo se ha de hacer el pedrestal que muestra la traça de piedra berroqueña con sus molduras, $\mathrm{y}$ a de tener de alto asta lo alto del altar.

-Ansimismo se an de hacer los lienços de pinturas que muestra la traza de mano de Francisco Camilo o Antonio ban de Pere o Francisco Xinés, elixiendo uno de los tres a satisfación de la señora abadesa del dicho convento y del padre fray Pedro Sedeño y Juan de Varoja, vicario y mayordomo de él, u de los que lo fuesen.

-Toda la qual dicha obra en la forma que ba dicha el dicho Sebastián de Venabente a de dar acavada y asentada en toda perfección y a satisfación del dicho conbento dentro de año y medio que corre y se quenta desde oy día de la fecha desta escriptura, y pagado 
el dicho plaço, no lo haviendo cunplido, quiere y consiente ser apremiado a ello por la vía y remedio que más aya lugar de derecho y sin perjuicio dello el dicho convento a de poder concertarse con otro qualquier maestro del dicho arte para que acave el dicho retablo en la forma dicha, y por lo que más costare de la cantidad que aquí se dirá, y las costas y daños, yntereses y menoscavos que en raçón dello se siguieren y recrecieren al dicho convento, quiere y consiente ser executado en virtud desta escriptura, y la declaración con juramento de la señora abadesa que a la saçón fuere dél y de su mayordomo en que lo deja y difiere con relevación de otra prueba.

-Y para mayor seguridad y firmeça de que el dicho Sebastián de Venabente cunplirá con hacer el dicho retablo en la forma dicha, dio por su fiador a Juan Bauptista Çavala, vecino desta villa, el qual que presente está lo aceptó, y haciendo como hace de deuda y fecho ageno suyo propio sin que contra el principal sea que no ha de ser necesario hacer escusión ni división ni otra diligencia alguna, cuyo beneficio y las leyes deste caso renuncia y juntamente con el susodicho y de mancomún con renunciación de las leyes de la mancomunidad como en ellas se contiene, se obliga a que el dicho Sebastián de Venabente ará el dicho retablo en la forma y según y como ba referido sin que falte a cossa alguna, y en defecto de no lo cumplir el susodicho, el otorgante como tal fiador lo cumplirá y pagará de sus vienes la cantidad que huviere recivido y todo lo que contra el dicho Sebastián de Venabente se juzgue y sentenciare y dejara de cumplir por vía executiba y todo rigor de derecho, y a ello se obliga con su persona y vienes muebles y raices havidos y por haber.

-Las dichas señoras abadessa, vicaria y discretas se obligan de dar y pagar al dicho Sebastián de Venabente por el dicho retablo acavado y asentado en la forma dicha a toda costa de manos y materiales treinta mill reales de vellón en esta manera: tres mill reales luego de contado, cinco mill reales para fin de febrero del año que viene de seiscientos y sesenta y quatro, otros cinco mill reales para fin de junio del dicho año, quatro mill reales para fin de otubre del dicho año, otros quatro mill reales para fin de febrero de seiscientos y sesenta y cinco, cinco mill reales para fin de junio del dicho año, y los quatro mill reales restantes cumplimiento a los dichos treinta mill reales el día que estubiere acavado y asentado el dicho retablo en toda perfección y por qualquiera de las pagas que dejaren de hacer quieren y consienten ser executadas en los vienes y rentas del dicho conbento y por más las costass de la cobrança.

-Con las quales dichas condiciones y las demás que sean necesarias para la firmeça y validación de tal escriptura la hacen y otorgan para cuyo cumplimiento dan su poder cunplido a las justicias y jueces conpetentes cada uno a las de su fuero para su execución a quien se someten, y especialmente las dichas señoras abadesas y discretas a la jurisdición de monseñor nuncio de Su Santidad en estos reynos de España y vicario desta villa, y los dichos Sebastián de Venabente y Juan Bauptista Çavala a los señores alcaldes de la casa y corte de su magestad, corregidor y thenientes desta villa de Madrid, y cada uno ynsolidum, y renunciaron su propio fuero y leyes de su favor y lo recivieron por sentencia definitiva de juez competente pasada en cosa juzgada y así lo otorgaron ante mi el dicho scrivano, y lo firmaron a quien doy fee conozco, siendo testigos Juan Muñoz Vello y Bartolomé Cortés de la Maza y Joseph..., vecinos desta dicha villa, ansimismo lo firmaron el padre fray Esteban de Utrilla, vicario del dicho convento y Juan de Varoja su mayordomo, con cuya ynterbención y asistencia se hiço 
y otorgó esta escriptura. Doña Ana de Murias y Valdés, abbadesa. Doña Ana Tello. Doña Catalina de Prado. Doña Juan de Motoia, bicaria. Doña Beatriz Cercito. Doña María Pichón. Doña Lucrecia de Salinas. Doña Jacinta de Reynoso. Sor Luisa de la Paz. Fray Esteban de Utrilla. Joan de Baroja. Juan Bapptista Zavala. Sebastián de Benabente. Ante mi, Antonio de Vega.

Fray Alonsso de Salaçar, calificador del suppremo real consexo de la santa y general ynquisición, vicario provincial y siervo desta santa provincia de Castilla de la regular observancia de nuestro padre San Francisco a la madre abbadesa y religiosas de nuestro convento de Santa Clara desta villa de Madrid, salud y paz en el Señor, por quanto vuestras reverendas nos an echo relación que necesitan de hacer un retablo para el altar mayor de la yglesia de esse dicho nuestro convento para que con mayor decencia se celebren los oficios divinos, y es assí que vuestras reverendas se an convenido con Sebastián de Venavente, escultor vecino desta dicha de Madrid, en que le a de hacer con calidad que esse nuestro convento se obligue a darle treynta mill reales de vellón, y para hacer el contrato nos piden vuestras reverendas nuestra facultad y licencia como a su lexítimo prelado que somos. Por tanto, viendo es justificada la petición de vuestras reverendas obra de piedad y religión, en virtud de las presentes concedemos dicha licencia en la mexor forma según y como se nos pide con calidad que en las escrituras que se hicieren se obligue esse dicho nuestro convento a dar treynta mill reales de vellón a dicho Sebastián de Venavente, y assí dicho Sevastián de Venavente se a de obligar a hacer el retablo dando fiador lego y abonado a satisfación del mayordomo de dicho nuestro convento con las condiciones siguientes:

Que todo el retablo se a de hacer de madera de pino de Balsaín seca y limpia de nudos con muy buenos ensanblajes en todas las partes que convengan para su duración; y assimismo se a de hacer la custodia que muestra la traça con muy buenos ensanblajes, y se an de hacer en dicha custodia puertas que se oculten para descubrir el Santíssimo en las festibidades, aciendo torno para ello; y en el pedestral de dicha custodia se a de hacer caja como muestra la traça para que esté colocado el Santíssimo Sacramento; y en el pedestral del retablo se an de hacer los adornos de fruteros que muestra la traça y las colunas que muestra la traça se an de hacer estriadas derechas como muestra la traça y los capiteles de ojas arpadas y los quadros principal y del remate se an de hacer de tarjetas como muestra la traça, y en las entrecalles de dicho retablo se an de hacer las tarxetas y fruteros que muestra la traça y tallar el quadro que guarnece el lienço de cada entrecalle, y assimismo se a de hacer los adornos de talla que muestra la cornissa, con la tarjeta que biene en medio adornando el cuadro; y assimismo se a de hacer la talla que muestra el remate del cerramiento con su tarjeta como muestra la traza; y todo dicho retablo se a de dorar con oro de muy buen color de lo que vate Manuel Martín, batidor de oro desta corte, y todo dicho retablo y custodia que muestra la traça se a de aparejar para dorar con las manos de aparejo que convenga para su duración, y assimesmo se a de dorar toda la talla y colorirla sobre oro con muy buenas colores, y barneçerlas para que no se oscurezcan, y hacer de grafío las lavores que mejor parezcan; y assimismo se a de hacer el pedestal de piedra que muestra la traza con las molduras que muestra la traza, y a de tener de alto hasta lo alto del altar; y assimesmo ha de hacer los lienzos de pinturas que muestra la traza de mano de Francisco Camilo o Antonio ban de Pere o Francisco Jinés, elijiendo uno 
de los tres a satisfación nuestra, de la madre abbadesa, del padre fray Pedro Sedeño y mayordomo de dicho nuestro convento, y en esta conformidad se harán las escrituras y tratados que necessario fueren, con calidad y condición que si pareciere el primer papel de las condiciones de dicho retablo que dio dicho Sebastián de Venavente firmado de su nombre se debe estar a él, y siempre el precio ha de ser treynta mill reales de vellón, y echas en esta forma las escrituras lo confirmamos y ratificamos desde aora para entonces como si a verlas hacer y otorgar nos halláremos presentes, ynterponiendo nuestra autoridad y decreto judicial según que de derecho se requiere $\mathrm{y}$ es necesario, en testimonio de lo qual mandamos dar y dimos las presentes firmada de nuestra mano, alladas con el sello maior de nuestro oficio y refrendarlas de nuestro ynfrascripto secretario en este nuestro convento de San Francisco de Madrid en quatro de otubre de mill y seiscientos y sesenta y tres años. Fray Alonso de Salaçar, vicario provincial. 